\title{
O aluno cego: preconceitos e potencialidades
}

\author{
Sylvia Nunes \\ José Fernando Bitencourt Lomônaco
}

\section{Resumo}

Este artigo analisa a cegueira, os preconceitos a ela associados e as potencialidades de pessoas cegas, especialmente do aluno cego. Salienta a ênfase dada ao sentido da visão no processo de aquisição de conhecimentos e considera os preconceitos comumente associados à capacidade de aprendizagem do cego.

Palavras-chave: Cego, deficiente visual, preconceito.

\section{The blind student: prejudices and potentialities}

\begin{abstract}
In this paper we analyze blindness, the prejudices associated to it and the potentialities of the blind student. We highlight the emphasis given to the ability to see in the process of knowledge acquisition and we take into account the prejudices related to the learning skills of blind people.

Keywords: Blind, visually disabled, prejudice.
\end{abstract}

\section{El alumno ciego: prejuicios y potencialidades}

\section{Resumen}

Este artículo analiza la ceguera, los prejuicios que se le relacionan y las potencialidades de personas ciegas, especialmente del alumno ciego. Además, se destaca el énfasis dado al sentido de la visión en el proceso de adquisición de conocimientos y considera los prejuicios frecuentemente asociados a la capacidad de aprendizaje del ciego.

Palabras clave: Ciego, discapacidad visual, prejuicio.

\section{Introdução}

A visão que o cego tem do mundo é de uma riqueza única, incomparável e deve passar a ser vista como uma apreensão integral da realidade, não uma carência de visão, não uma castração de um órgão, mas a existência suficiente de um ser humano completo. (Monte Alegre, 2003, p.12)

Quando se pensa em cegueira, algumas indagações são comuns: como é a vida cotidiana sem a visão? O que o cego é capaz de fazer? Que tipo de vida pode levar? Como ele é capaz de aprender? Neste trabalho, tais indagações são analisadas e, a partir desta análise, a situação do cego na vida escolar é discutida.

A ideia do presente artigo surgiu da percepção sobre o reduzido número de artigos referentes ao aluno cego, suas características, os preconceitos que o cercam e suas potencialidades como aprendiz. Pressupomos que profissionais das áreas de Psicologia e Educação devem ter conhecimentos sobre os diferentes tipos de deficiências, as limitações reais impostas por cada deficiência e, principalmente, as infinitas possibilidades de desenvolvimento e aprendizagem desses sujeitos. Assim, objetiva-se neste artigo apresentar e analisar informações sobre a cegueira e o aluno cego a 
partir da literatura teórica e de pesquisas na área de modo a salientar suas reais limitações, mas, ao mesmo tempo, enfatizar as potencialidades do aluno cego, uma vez que tais possibilidades estão com demasiada frequência encobertas pelo manto dos preconceitos.

\section{I. $O$ que é cegueira?}

A cegueira é uma deficiência visual, ou seja, uma limitação de uma das formas de apreensão de informações do mundo externo - a visão. Há dois tipos de deficiência visual: cegueira e baixa visão.

Devido às muitas discussões sobre a deficiência e seus estigmas, é comum a preocupação com os termos utilizados a fim de que eles não sejam pejorativos nem reflitam preconceitos. Em face disto, algumas pessoas preferem o termo deficiente visual à palavra cego. Todavia, esses termos não são equivalentes. O conceito de deficiência visual é mais abrangente visto que engloba não só a cegueira como também a baixa visão. Embora haja quem acredite ser o termo "cego" preconceituoso ou pejorativo, não compartilhamos dessa premissa. Utilizamos a palavra por seu caráter descritivo: cego é aquele que é privado de visão, segundo o dicionário Houaiss. E é dessa realidade que estamos tratando. Não há preconceito na utilização do termo cego. O preconceito está em pressupor que o cego é um sujeito menos capaz.

Segundo Amiralian (1997), a primeira preocupação com a cegueira foi a da medicina, que a percebia como uma consequência de doenças e buscava minimizar essa deficiência com o objetivo de tornar a pessoa normal novamente. Os médicos se interessavam sobre quanto uma pessoa com deficiência visual era capaz de ver, o que levou à definição de medidas para avaliar a capacidade visual. A medida mais usada, desde então, é a avaliação de duas funções oculares: acuidade visual - que consiste em discriminação de formas - e campo visual - relativo à capacidade de percepção da amplitude dos estímulos. A capacidade visual é avaliada por essas medidas, com todas as correções ópticas possíveis (óculos, lentes etc.). No entanto, começou-se a perceber que alguns cegos, com a mesma medida de acuidade visual, apresentavam capacidade visual diferente. Alguns deles, inclusive, ao aprender o sistema braile, conseguiam utilizar a visão residual para ler o braile com os olhos, isto é, algumas pessoas diagnosticadas como cegas aproveitavam a pouca visão que tinham para apreender as informações do mundo. Isto levou à formulação da distinção entre cegueira e baixa visão. Assim, a partir de 1970, o diagnóstico de deficiência visual deixou de considerar apenas a acuidade visual para avaliar as formas de percepção do sujeito: se ele apreende o mundo por meio do tato, olfato, cinestesia etc., esta pessoa é considerada cega; se, no entanto, tiver limitações da visão, mas ainda assim conseguir utilizar-se do resíduo visual de forma satisfatória, então, seu diagnóstico é de baixa visão. Tal concepção permite a indicação de auxílios ópticos (óculos, lentes de aumento específicas, lupas etc.); concessão de benefícios sociais e medidas educacionais (como o uso do código braile ou letra comum).
Para compreender melhor a condição de cegueira e a forma como ela é vivenciada pelo indivíduo, é importante conhecer a idade e a causa da perda visual. Segundo Amiralian (1997), os cegos que perdem a visão a partir dos cinco anos são considerados cegos adventícios ou adquiridos. Os casos de cegueira anterior a essa idade são chamados de cegueira congênita. A delimitação da idade de cinco anos para o diagnóstico de cegueira adquirida é fruto de pesquisas que não identificaram memória visual em cegos que perderam a visão antes dessa idade.

A autora afirma que, quanto mais cedo ocorre a perda da visão, mais essa condição influencia o desenvolvimento do sujeito e, quanto mais tarde a cegueira se apresenta, mais as características de personalidade anteriores à perda têm peso maior na formação do indivíduo.

A ausência da visão é um fenômeno complexo e diverso. As causas da deficiência, o momento e a forma da perda visual (progressiva ou repentina), o contexto psicológico, familiar e social influenciam o modo como a pessoa vive sua condição de cegueira. Assim, ainda que possamos pensar em pontos comuns entre os cegos - principalmente no que diz respeito às formas de percepção - o desenvolvimento de cada um é peculiar, como o é de todo vidente, o que justifica pensarmos que o desenvolvimento da pessoa com cegueira está muito mais próximo ao de outras pessoas com características próximas (idade, condição socioeconômica, influência cultural etc.) do que a de outro cego. No entanto, ainda que não exista apenas um caminho de desenvolvimento para os cegos, algumas condições são importantes para melhorar e/ou viabilizar suas condições de aprendizagem.

Como já dissemos, em casos de baixa visão, recursos ópticos podem ser utilizados para maximizar o resíduo visual. O mesmo não ocorre com a pessoa cega. Então, é preciso fazer com que a informação visual chegue até ele por outras formas. Para tal, outros canais sensoriais devem ser utilizados, como o tato e a audição.

A importância da linguagem no desenvolvimento humano é inquestionável. Para o cego, a linguagem assume um papel ainda maior, porque as informações visuais a que ele não tem acesso podem ser parcialmente verbalizadas. Nesse sentido, Lira e Schlindwein (2008), que discutem a inclusão da criança cega na escola por uma leitura vigostskiana, relacionam a linguagem e as funções psíquicas superiores para o cego:

A criança cega pode perfeitamente se apropriar das significações de seu meio e participar das práticas sociais, pois dispõe do instrumento necessário para isso - a linguagem. Além disso, a concepção de que, com o desenvolvimento das funções psíquicas superiores, o homem transforma sua relação com o mundo e nela introduz a dimensão semiótica, minimiza a dimensão da perda decorrente da cegueira. (Lira \& Schlindwein, 2008, p. 187)

Segundo Amiralian (1997), o cego substitui o que ele não vê por meio da linguagem, o que pode justificar algumas palavras não compreensíveis ou parcialmente compreensí- 
veis que eles falam. Além disso, o sujeito cego percebe o mundo por meio de todos os sentidos que não a visão (tato, olfato, paladar, audição), mas o significado das coisas lhe é transmitido, em sua maioria, por videntes que utilizam muito menos esses sentidos e muito mais a visão como fonte de informação e conhecimento. A consequência deste impasse é que a pessoa cega tem que fazer constantes "ajustes" entre aquilo que ela conhece por meio de suas percepções e aquilo que chega pela fala dos que a rodeiam.

Rabêllo (2003) afirma que algumas pessoas cegas “(...) se tornam extremamente sensíveis aos matizes de inflexão, de volume, de cadência, de ressonância e das várias intensidades dos sons das falas dos outros, que passam despercebidos aos videntes" (p. 78). É por meio da linguagem e das percepções táteis e cinestésicas que podemos explicar seu desenvolvimento cognitivo, uma vez que a linguagem assume ainda mais uma função organizadora e planejadora, fundamental para o desenvolvimento humano.

Em relação ao tato, Ochaíta e Rosa (1995) diferenciam dois tipos, baseados em Gibson: tato passivo - recepção da informação de forma passiva e não intencional pela pele e pelos tecidos subjacentes, por exemplo, sensação de calor causada pela roupa - e tato ativo ou sistema háptico - busca de informação de modo intencional por meio do toque. Neste tipo de tato, estão envolvidos não só a pele e os tecidos subjacentes, mas “(...) receptores dos músculos e tendões, de maneira que o sistema perceptivo háptico capta a informação articulatória motora e de equilíbrio" (Ochaíta \& Rosa, 1995, p.185).

Em comparação à visão, o tato é uma forma mais lenta de captação da informação. Isso porque a exploração háptica se dá de forma sequencial. Por exemplo, o cego precisa percorrer uma mesa para conhecê-la, enquanto a visão permite uma identificação mais rápida. No entanto, Batista (2005) lembra que não é só o tato que tem o caráter sequencial: música, discurso, livros, textos, todos são formas sequenciais de transmissão de informação e, nem por isso, são consideradas melhores ou piores do que a informação captada visualmente. Muito pelo contrário, é comum ouvirmos que ler um livro permite um aprofundamento maior da história do que ver o filme correspondente.

O tato possibilita o conhecimento por meio das características dos objetos: textura, formato, temperatura etc. Mas ele é mais útil para objetos próximos e permite menos informações no caso de objetos grandes e/ou distantes. Esta possibilidade de discriminação pelo tato e pelos outros sentidos leva a crer que o uso dos sentidos pelo cego não é uma mera compensação do órgão falho, mas envolve uma reorganização biopsicossocial, que permite o acesso e o processamento de informações.

Camargo, Nardi e Veraszto (2008), ao pesquisarem a comunicação entre alunos com deficiência visual e seus professores, afirmam que "(...) utilizando-se maquetes e outros materiais possíveis de serem tocados, vinculam-se os mencionados significados a representações táteis e, por meio da estrutura mencionada, esses significados tornam-se acessíveis aos alunos cegos ou com baixa visão" (p.3401)
Isso significa que, sem acesso a materiais gráficos (desenhos e figuras em relevo) em situações de aprendizagem, restringe-se uma ampla possibilidade de conhecimento do mundo para o deficiente visual.

Mas, embora o tato seja uma importante via de informação para o sujeito cego, obviamente não é a única. O sistema cinestésico é um dos sistemas que fornecem informações sobre a orientação espacial, o movimento e o equilíbrio, possibilitando a percepção de posição, da direção do vento, da velocidade do movimento e orientação do corpo.

Uma vez que nem todos os objetos podem ser percebidos diretamente pelo tato, alguns conceitos só podem ser entendidos pelas crianças por explicações orais ou outras analogias, como maquetes ou outros tipos de representação. Também o olfato e a gustação são dois sentidos importantes para o desenvolvimento da criança cega. A gustação auxilia na apreciação dos alimentos e o olfato ajuda o cego a reconhecer pessoas, objetos, caminhos etc.

Pensando nas possibilidades de compreensão do mundo pelos sentidos que não a visão, é interessante refletir sobre trabalhos que enfocam a vivência da arte pelo sujeito cego. Oliveira (2002), por exemplo, em sua obra Do essencial invisível: arte e beleza entre os cegos, discorre sobre as possibilidades de experiência estética dos cegos. A questão que fundamenta o livro é: o cego, em função de sua perda visual, é capaz de vivenciar a experiência estética? É evidente que, por trás da pergunta, está a noção de que a estética se limita ao visual. $\mathrm{O}$ autor discorda desta noção e defende que a arte não é apenas visual e, portanto, é acessível ao cego.

Em primeiro lugar, ele afirma que a arte não se restringe à pintura, à escultura e à arquitetura, pois também a literatura, a dança e a música são expressões artísticas. Ou seja, as artes e a beleza não são usufruídas apenas pela visão, mas também pelo tato e pela audição, como ocorre, por exemplo, quando da apreciação de esculturas pelo tato e de músicas e literatura pela audição. Oliveira (2002) parte de uma concepção de beleza que considera a percepção da unidade em meio à diversidade, como pressuposto de vivência estética. Este princípio de unidade não se restringe à percepção visual: o tato pode inferir beleza ou não em contornos e texturas tridimensionais. Há limitações nessa percepção de beleza porque diversas estruturas tridimensionais não são inteiramente captadas pelo tato. No entanto, nesse pensamento, o cego é capaz de ter a experiência estética por meio de seus sentidos e suas vivências.

Ferrari e Campos (2001) partem de outra definição de estética para falar da beleza para os cegos. As autoras afirmam que há uma intrínseca relação entre beleza e prazer, não estando a beleza unicamente ligada à imagem visual. Assim, por mais que a experiência estética esteja baseada na experiência sensorial - seja qual for o sentido - ela só é possível pelo uso conjunto da razão. Se a apreciação da beleza se dá pela inter-relação entre sentidos e racionalidade, e não unicamente pela visão, então, ela é possível ao cego. Ele é capaz de experenciar a beleza por meio do toque, da cinestesia, da audição etc. 
As coisas do mundo têm qualidades múltiplas, muitas delas não visuais. É a partir dessas qualidades que temos que pensar o trabalho com cegos. Propostas como as de Ferrari e Campos (2001), em que crianças e adultos deficientes visuais visitam museus, mostram que estes não são espaços culturais predominantemente visuais. Pois, tanto no que se refere à apresentação quanto à divulgação do acervo, há possibilidades de experiências estéticas acessíveis aos deficientes visuais.

O teatro é outra forma de vivência estética e cultural para o cego. Vale lembrar que a palavra "teatro" tem, em seu histórico etimológico, relação com o contemplar algo pela visão. Assim, em um primeiro momento, a experiência teatral estaria restrita a quem vê: como ator e como espectador. A lógica da concepção etimológica de teatro e a exclusão cultural que esse segmento da população vive justificam a dúvida sobre essa experiência por parte do cego. Mas Rabêllo (2003), em sua tese de doutorado, mostra o quanto essa experiência é possível e enriquecedora para o desenvolvimento do deficiente visual, tanto pela oportunidade de trabalho sensorial, corporal e expressivo, quanto pelo acesso a uma importante forma de manifestação cultural por meio de algumas adaptações e ênfase nas informações e vivências não visuais necessárias para a experiência teatral.

Em suma, a aquisição de informações pela pessoa cega se dá pela conjunção das sensações táteis, cinestésicas e auditivas aliadas às experiências mentais passadas já construídas pelo sujeito. Isso quer dizer que, sem a visão, o cego percebe a realidade de forma diferente do que as pessoas que veem. O que não quer dizer que a percepção do cego seja melhor ou pior. A questão está na diferente organização sensorial de cegos e videntes. É nesse sentido que Vygotsky (1934/1997) afirma que a vivência da cegueira não é como a do vidente de olhos tapados. O cego de nascença percebe o mundo de forma diferente e só experimenta a cegueira como deficiência por meio de interações sociais que Ihe mostram isso.

Assim, a cegueira por si só não é um impedimento ao desenvolvimento. Há a imposição de caminhos diferenciados devido à ausência da visão, mas o desenvolvimento do cego é pleno de possibilidades e limitações como o de qualquer ser humano. É o que também parece pensar Amiralian (2007) que, após estudar o desenvolvimento emocional de crianças cegas congênitas, afirma “(...) Há, portanto, entre as crianças com cegueira congênita, uma grande variedade de possibilidades de desenvolvimento" (p.130).

No entanto, a deficiência visual - assim como os outros tipos de deficiência - assume na sociedade em que vivemos uma diferença que é considerada uma desvantagem. A forma como a cegueira tem sido concebida restringe o que a criança é à sua falta de visão, pois o enfoque é dado à imperfeição e à falta. Assim, quando um vidente conhece um cego, é comum que a relação se estabeleça primeiro com a deficiência e, depois (talvez), com o ser humano que existe para além da cegueira.

Podemos pensar que, ao considerar as particularidades da cegueira, o profissional que trabalha com alunos ce- gos estará mais bem capacitado a estabelecer vínculos com os mesmos, entendendo que eles têm a cegueira com uma condição (dentre muitas outras que esse indivíduo também tem: classe social, gênero, cor/raça etc.). É inegável que tal condição impõe limitações ao seu processo de aprendizagem e ao seu desenvolvimento como um todo, mas, uma vez que as informações do mundo podem chegar por diferentes e variadas vias, o indivíduo cego tem tantas possibilidades de se desenvolver quanto as crianças videntes.

\section{Como o cego é visto?}

Em terra de cego quem tem olho é rei, e em terra de olho quem é cego é o quê?

Em nosso mundo visual, muitas informações são tratadas como exclusivamente visuais quando, na verdade, não são. Podemos perceber isso em algumas ações como encontrar objetos em bolsas, digitar números de telefone, tocar instrumentos, vestir-se etc. A visão é, possivelmente, o "guia" dessas ações, mas sua ausência não é demasiadamente prejudicial para a execução da ação (Batista, 2005).

Porém, como vivemos em um mundo de videntes, à visão é dado um papel essencial no desenvolvimento humano e sua ausência assume, muitas vezes, uma dimensão maior do que ela realmente tem.

Essa ideia de restrição do desenvolvimento do cego justifica-se pela supervalorização da visão na aquisição do conhecimento. Existem autores que estimam ser a visão a responsável por $80 \%$ do conhecimento, como Oliveira (2002). Batista e Enumo (2000) questionam essa afirmação considerando que, que ainda que a visão seja uma importante via de informação, ela não é a única.

Tal ideia também está amplamente arraigada em nossa linguagem. No cotidiano, é fácil perceber que utilizamos o verbo ver não só para a ação de olhar algo, mas também no sentido de conhecer. Por exemplo, com muita frequência, falamos: "Você viu o que aconteceu com fulano?". Tal uso do verbo "ver" tem mais relação com o conhecimento do fato do que exclusivamente com o ato de ver. Essa atribuição de significados para além da visão não acontece apenas com esse verbo. Muitos outros termos derivados das palavras ver e olhar também estão imbuídos de outras significações relacionadas à supremacia da visão, como, por exemplo: visões de mundo, pontos de vista, revisão, mau olhado, amor cego, fé cega, olho gordo, olho comprido, frieza do olhar, estar de olho etc.

Amiralian (1997) nota dois polos opostos quando se fala em cegueira: a) o cego pode ser visto como indefeso, como um coitado; ou como detentor de um saber sobrenatural, mais capacitado para desvendar mistérios do que os videntes; b) em relação à bondade/maldade também existe esse paradoxo: ou o cego é percebido como estritamente bom, ou como o vilão da história.

Debora Kent (1989) também evidencia isso ao estudar a concepção de cegueira na literatura. De modo geral, há uma oscilação entre bondade ou maldade extremas; sabedoria; punição dos pecados; intensa relação com Deus 
etc. Essas características são abordadas como se fossem inerentes à falta de visão.

As pessoas cegas, frequentemente, são tidas como especiais, como portadoras de características profundamente diferenciadas das outras pessoas, tanto na literatura como na mídia em geral. Esse preconceito impede que se perceba o cego como um ser humano.

O estereótipo do cego está relacionado à forma como historicamente ele foi visto. Vygotsky (1934/1997) define três momentos principais na concepção de cegueira. O primeiro momento é chamado período místico e compreende a Antiguidade, Idade Média e parte da Idade Moderna. Nesse período vigoraram duas noções principais: ou o cego era considerado alguém indefeso, infeliz, que vivia em desgraça, ou era tratado com respeito pelos poderes místicos que se acreditava ter. Devido à falta de visão, o sujeito era visto como mais capaz de se desenvolver espiritualmente, pois se entendia que ele estava livre do envolvimento nas ilusões mundanas.

Em nosso meio, a primeira autora deste trabalho participou da realização de uma pesquisa sobre as concepções de cegueira congênita em alunos do primeiro e quarto anos de um curso de Pedagogia. Um dos entrevistados expressou que a pessoa cega "(...) se desenvolve em um âmbito muito mais espiritualista do que materialista pelo fato dela não concretizar o que ela vê" (Viegas e cols., 2004). Nessa curta frase, podemos perceber claramente esta ideia de um maior desenvolvimento espiritual do sujeito cego e também a incompetência em "concretizar" as informações que recebe do mundo. Como salienta Amiralian (2002), o mundo mental do cego é um enigma para o vidente. Natural que o seja, dada à diferença que a visão provoca. No entanto, conceitos distorcidos como este deixam o cego em desvantagem, já que a ele são atribuídas capacidades e limitações que nada têm a ver com a falta de visão.

Também na pesquisa de Caiado (2003, p.35), a ideia de incapacidade/espiritualidade fica evidente na seguinte fala: "Há o professor que acredita que o deficiente visual não aprende porque é um deficiente global e, outros, que acreditam que, porque ele não tem a visão, desenvolveu uma inteligência extraordinária".

O segundo momento, denominado período biológico e ingênuo, ocorreu durante o lluminismo (século XVIII). Como sabemos, a ciência passa a ser bastante valorizada nesse período, reduzindo-se muito o espaço para explicações metafísicas. Ao mesmo tempo, cresce a necessidade de "esclarecer" a população em geral e, assim, são criados vários centros de educação em massa, principalmente na Europa. Todos esses acontecimentos dão um novo sentido à cegueira, que passa a ser vista como objeto de estudo científico. Além disso, inicia-se o movimento de educação dos cegos por meio da criação de institutos e escolas específicos para eles. Este movimento educacional permitiu maior inclusão social da pessoa cega.

Data deste período a criação da teoria da substituição, segundo a qual a falta de um órgão seria compensada pelo melhor funcionamento de outros. $\mathrm{O}$ salto qualitativo entre $\mathrm{O}$ primeiro e o segundo período é notável, uma vez que a ex- plicação mística para a cegueira cede lugar a uma teoria que pressupõe a capacidade de adaptação do cego. No entanto, mesmo este segundo período ainda guarda uma concepção equivocada do cego, qual seja, a de que a compensação da falta de visão pelos outros sentidos é simples e automática. Ainda hoje existem práticas pedagógicas que enfatizam unicamente a estimulação dos outros sentidos - o que é consequência de uma concepção biologizante e restrita de ser humano.

Num estudo sobre conceituação de cegueira por estudantes do primeiro e quinto anos de Psicologia de uma universidade estadual paulista, mais uma vez esta ideia foi expressa nas respostas dos participantes agrupadas na categoria Compensação Sensório-Cognitiva, que inclui termos referentes à compensação da visão pelos outros sentidos ou às capacidades cognitivas do cego como um processo automático e natural, e não como um resultado da aprendizagem passível a qualquer ser humano (Lomônaco, Nunes, \& Sano, 2004).

E, finalmente, o período científico ou sociopsicológico é marcado pela percepção do cego como capaz de se reorganizar para compensar a deficiência visual. Essa compensação não se limita ao desenvolvimento dos outros órgãos dos sentidos, mas à reorganização da vida psíquica por inteiro, a fim de compensar o conflito social advindo da deficiência do órgão. Aqui, podemos perceber outro salto qualitativo entre o segundo e o terceiro períodos. De uma concepção meramente biológica, o homem passou a ser visto como um ser social e histórico que, por meio dos grupos sociais de que faz parte, desenvolve uma linguagem e, ao se comunicar, constrói significados para si e para os outros.

Vygotsky (1934/1997) não nega as limitações da cegueira enquanto restrição biológica, mas afirma que, socialmente, não há limitações, porque o cego, por meio da palavra, pode se comunicar e apreender significados sociais. No entanto, a inter-relação do indivíduo cego com o ambiente não se dá sem conflitos. Mas, segundo o autor, é devido ao fato do conflito existir que há forças para sua superação.

Claro que, devido à limitação visual, o indivíduo cego vai precisar de um ambiente diferenciado e adaptado, que dê conta de garantir a satisfação de suas necessidades. E toda essa vivência diferenciada define uma estrutura mental diferente daquele que vê, pois a pessoa cega precisa usufruir de outros caminhos para conhecer o mundo, o que marca outras formas de processo perceptivo e, por consequência, da estruturação e organização do desenvolvimento cognitivo. Este fato pode ser evidenciado com os conceitos de espaço e tempo. No caso do espaço, os elementos que dão as informações espaciais são diferentes para o vidente e para o cego: quem vê se utiliza muito mais da visão do que dos outros sentidos, enquanto o cego se utiliza mais de uma exploração tátil-cinestésica do ambiente. Levando em conta esses aspectos, Amiralian (2002) afirma:

Devemos ter sempre em mente que, para os videntes, o mundo mental dos cegos é um conceito nebuloso, organizado por analogias ou inferido de situações que consideramos semelhantes às deles. Dessa mesma 
maneira, o mundo mental dos videntes é construído pelos cegos. Por exemplo, para nós é muito difícil pensar em uma representação mental sem a imagem visual, ou o que seja o conceito tátil-cinestésico de cadeira, assim, como para os cegos congênitos, a visualização dos objetos é um dado impossível. (p. 207)

\section{O cego na sala de aula}

Amiralian (2002) considera duas concepções de inclusão do deficiente visual. A primeira proposta foi influenciada pela prática estadunidense e está mais voltada a programas de treinamentos que visam tornar o deficiente visual mais parecido com o vidente. Esse processo, chamado normalização, é bastante criticado. Primeiro, porque não é possível tornar uma pessoa aquilo que ela não é. Além disso, a questão da normalização traz nas entrelinhas a ideia de que ser deficiente visual é ser inferior e faltante. Isto dificulta ainda mais a vivência dessa condição pelo deficiente, porque se todas as suas percepções e conceitos são considerados inferiores, então, resta a esta pessoa a busca constante dos conceitos visuais que não lhe são acessíveis, a não ser pela fala dos videntes, o que os deixa novamente dependentes.

É possível outra forma de inclusão do deficiente visual que $\mathrm{o}$ aceite sem valorizar demais as suas incapacidades, mas buscando respeitar o que ele é. Essa concepção de inclusão não enfoca os limites e déficits das pessoas cegas, mas busca compreender a forma como essa pessoa se constitui e percebe o mundo, de modo a não querer transformar os cegos em videntes, e nem tampouco impor conceitos, padrões e valores dos que veem. Em vez disso, tenta entender as limitações da ausência de visão e analisa as condições de vida na família, escola e em outros grupos de referência que possam facilitar o desenvolvimento desse indivíduo.

O aluno cego, em sua vida escolar, necessita de materiais adaptados que sejam adequados ao conhecimento tátil-cinestésico, auditivo, olfativo e gustativo - em especial materiais gráficos tateáveis e o braile. A adequação de materiais tem o objetivo de garantir o acesso às mesmas informações que as outras crianças têm, para que a criança cega não esteja em desvantagem em relação aos seus pares.

A educação do deficiente visual é marcada pela relação intrínseca com o atendimento especializado, capaz de suprir as necessidades especiais advindas da falta de visão e assegurar o ensino formal deste aluno. Esse atendimento especializado deve ser garantido pela chamada educação especial.

A educação especial é uma modalidade de ensino que deve caminhar paralelamente ao ensino regular, em todos os seus níveis: educação infantil, ensino fundamental, médio e superior. Esta concepção de modalidade não está isenta de discussões e divergências. Pressupomos que o ensino especializado deve acompanhar a criança/pessoa com deficiência em toda a sua vivência educacional sem, com isso, se transformar em substituto do ensino regular. Segundo a Lei n. ${ }^{\circ} 5.540 / 68$, a função do professor especializado é a de atuar como docente e especialista. Ele atua como docente porque é responsável por atividades de ensino e aprendizagem e como especialista porque é um agente facilitador do processo educacional ao orientar a escola, a família e a comunidade. Dessa forma, a ênfase da atuação do professor especializado depende do lugar onde ele está desenvolvendo seu trabalho, que pode ser: classe especial, sala de recursos ou ensino itinerante.

A estigmatização do deficiente visual prejudica sua personalidade e autoestima. Por isso, é preciso um ambiente educacional o mais adequado possível para o desenvolvimento integral do cego. Monte Alegre (2003) constatou a falta de apoio especializado nas escolas comuns - ditas "inclusivas" -, tanto pela falta de materiais e recursos para o trabalho com as crianças cegas, quanto pela falta de preparo dos docentes da sala de aula comum, o que leva a um trabalho pedagógico técnico, espontaneísta e muitas vezes inadequado por não dar conta das necessidades do aluno cego. As professoras da sala comum de alunos com deficiência visual demonstraram incertezas sobre como lidar com esses alunos e desconhecimento dos materiais adaptados para o cego - inclusive o braile.

No entanto, algumas delas afirmaram que o convívio com alunos deficientes visuais permitiu a percepção das capacidades destas crianças, a superação de preconceitos e a representação da criança como um ser que tem "(...) características gerais de normalidade, de autonomia, de relações sociais satisfatórias, de virtudes cognitivas, curriculares, de desenho, de locomoção, verbais, do interesse pelo conhecimento e como merecedoras de uma projeção de futuro satisfatório" (Monte Alegre, 2003, p. 275).

Assim, ainda que o autor faça uma crítica aos poderes públicos pela falta de investimento e iniciativa na área de educação especial (em alguns casos, o professor compra os materiais com seus próprios recursos), o convívio escolar dessas crianças com professores abertos a situações novas e criativas não deixa de ser um ganho significativo. Claro que isso não pode ser motivo para não se lutar por melhores condições de ensino desta população, uma vez que isso lhe é de direito. Mas a experiência citada mostra o quão importante é a convivência com a diferença, se esta é respeitada. No entanto, se o professor não está preparado, ele pode demorar a perceber (se vier a perceber) a capacidade de seu aluno cego e, com isso, desperdiçar um precioso tempo da vida desse aluno, o que não ocorreria se o professor já tivesse em sua formação um contato e uma reflexão sobre a deficiência visual.

Masini (1994) analisa várias propostas de educação para deficientes visuais e nota que o referencial utilizado é o do vidente; deste modo, a comparação do deficiente visual com o vidente coloca o primeiro em constante desvantagem. Esse fato tem uma consequência grave para o deficiente visual, qual seja, a de não ser percebido como ele de fato é, mas sempre com o olhar daquilo que ele não é. Outro ponto levantado pela autora refere-se aos instrumentos propostos nos programas, que refletem uma concepção subjacente de processos mecânicos de aprendizagem, pois as tarefas baseiam-se em associação simples do mundo externo, des- 
contextualizadas da forma global de percepção do deficiente visual.

A concepção de cego com base no vidente, além de minimizar as possibilidades de entender o cego como ele realmente é, enfatiza suas limitações e não suas possibilidades. $E$ isso, em um mundo de videntes, faz com que o deficiente visual seja ainda mais prejudicado. Mas como um educador vidente pode ensinar um cego? Claro está que um vidente não tem como saber diretamente como se organiza o "mundo" do cego, pelo fato daquele usar a visão como sentido principal de suas ações. Mas isso não impede que pais, professores e profissionais possam ir além de suas experiências como videntes e consigam perceber que as possibilidades de aprendizagem de uma criança ou adulto com deficiência visual são tão grandes como a de qualquer ser humano, pois a visão não é a única fonte de informação.

A educação do deficiente visual pode ser orientada por um professor especializado, o que não quer dizer colocálo em uma escola especial. Ao contrário, o aluno deve ser regularmente matriculado em uma escola regular, mas receber o apoio de um professor especializado para assegurar a satisfação das suas necessidades, até o momento que isso for preciso.

Caiado (2003), num estudo sobre as vivências escolares dos cegos, entrevistou seis pessoas cegas cuja perda visual foi anterior à alfabetização e que aprenderam a ler pelo braile e no ensino regular. Dentre as categorias criadas pela autora para analisar as entrevistas, duas chamam a atenção: o preconceito vivido em sala de aula, em grande parte pela falta de preparo do professor, e a falta de recursos adaptados para os alunos cegos.

Essa falta de materiais adaptados fazia com que os alunos tivessem a fala do professor como único recurso pedagógico. Claro que a voz do professor é de extrema importância em sala de aula para qualquer aluno. No entanto, desenhos, mapas, fórmulas, escrita na lousa etc. são frequentemente utilizados para enriquecer a aula e facilitar a apreensão dos conteúdos. Nesses momentos, o que fazer com o aluno cego? Alguns poucos professores conseguiam fazer adaptações ou dedicavam uma atenção especial aos alunos cegos. Mas a maioria não fazia essa adaptação de recursos e deixava os alunos cegos excluídos de certos conteúdos, delegando unicamente a eles próprios a responsabilidade pela sua aprendizagem. Alguns pais de alunos cegos confeccionavam os materiais adaptados. Mas a maioria dos alunos relatou que concentravam todos os seus esforços na fala do professor: foi pela aprendizagem a partir do que o professor falava em sala que eles estudaram para provas escolares, vestibulares e concursos.

Também Camargo e cols. (2008) notaram a importância da fala na aprendizagem do aluno com deficiência visual. Entretanto, os autores, ao estudarem a comunicação em sala de aula no ensino de física, notaram as dificuldades comunicacionais ocorridas entre professores e alunos. As dificuldades mais frequentes referem-se à apresentação de conteúdos vinculados a representações visuais, sem a devida adaptação.
Tal dado nos mostra que não é pelo fato do professor falar que o aluno cego tem garantido o acesso ao conhecimento. São necessárias adaptações na fala do professor para que o conteúdo não seja estritamente visual. Para tal, é preciso lançar mão de outros recursos (como maquete, esquemas táteis, sonoros etc.), de modo a garantir que o aluno está compreendendo o que está sendo dito pelo professor.

Caiado (2003) lembra o quanto a educação dos alunos com deficiência no Brasil teve um histórico de assistencialismo e filantropismo, de modo a não ser vista como um direito, mas como uma ação benevolente de algumas pessoas. Só recentemente os direitos das pessoas com deficiência têm sido assegurados por lei e, como consequência, têm sido objeto de reivindicações e lutas - ainda que timidamente - para o cumprimento da lei.

Em decorrência do pouco conhecimento sobre a deficiência visual, os professores frequentemente têm baixa expectativa quanto à aprendizagem do aluno. A crença equivocada da pouca capacidade de aprendizagem do aluno cego prejudica-o muito, uma vez que tende a minimizar as propostas pedagógicas do professor. Outro ponto negativo quanto à educação do cego é a possibilidade do professor, por falta de preparo, adotar procedimentos educacionais tendo, como parâmetro, as formas de aprender do vidente. Em última instância, isso significa a recusa total do professor de encarar a deficiência e perceber suas possibilidades e limitações. Caiado (2003) nos dá um exemplo disso no depoimento de uma das participantes de sua pesquisa: "Essa professora, ao invés de falar comigo, perguntava para o meu companheiro do lado; outros professores não gostavam de ditar, porque já tinham passado a matéria na lousa" (p. 84).

O hábito de escrever a matéria na lousa como único recurso deve sofrer adaptações quando há um aluno cego em sala de aula. Não é possível ao professor simplesmente dizer para si e para os outros que esse é o seu jeito e que não pode mudar para não prejudicar os outros alunos. Esse tipo de atitude demonstra não só a dificuldade do professor, mas a cristalização de preconceitos que leva o aluno cego à exclusão dentro da lógica da inclusão: ele está em sala de aula, mas as barreiras atitudinais não estão favorecendo seu aprendizado.

Esse é um jogo perigosíssimo porque, se esses preconceitos não forem revelados, a mensagem da instituição escola é: estamos fazendo a nossa parte, estamos aceitando "alunos de inclusão", estamos incluindo. Mas, na realidade, nada foi alterado ou adaptado para esse aluno, que fica marginalizado dentro da sala de aula. Se ele não aprender, ou se desistir de estudar, a escola sentir-se-á eximida de culpa. É uma lógica cruel e, infelizmente, real.

Também Lira e Schlindwein (2008) notaram que professores de alunos cegos se negaram a mudar as estratégias de ensino em prol da aprendizagem do seu aluno. As pesquisadoras apresentam um estudo em que três estudantes universitários cegos foram entrevistados. O objetivo foi relacionar o percurso escolar com a vivência da inclusão/ exclusão. Várias dificuldades foram apontadas pelos entrevistados além da supracitada: falta de material em braile e 
de acessibilidade do ambiente físico. Segundo as autoras, os problemas de escolarização apontados não se referem a limitações intelectuais ou de abstração do cego, mas da falta de preparo do sistema educacional e da escola específica em que estavam estudando, pois não houve suficiente adaptação dos recursos didáticos para potencializar a aprendizagem dos alunos.

Montilha, Temporini, Nobre e Kara-José (2009) relatam uma pesquisa em que 26 alunos com deficiência visual, cegueira e baixa visão, com média de idade de 17 anos, responderam a um questionário sobre o seu processo de escolarização. Os resultados apontaram alto nível de repetência dos alunos. Além disso, a dificuldade mais apontada pelos sujeitos foi a de ler os livros didáticos. E a relação com o professor, dentre a relação com colegas e diretor, foi a mais escolhida como influente no processo de aprendizagem. Nesse sentido, podemos pensar que, segundo esses alunos, um bom relacionamento com o professor auxilia mais na compreensão dos conteúdos escolares. Porém, esse bom relacionamento nem sempre ocorreu, pois $73,1 \%$ dos alunos tiveram alto índice de repetência.

No estudo realizado por Nunes e Lomônaco (2008), alunos cegos de uma instituição especializada foram solicitados a definir conceitos concretos e abstratos. Nem todos os participantes apresentaram definições claras e corretas dos conceitos em questão, porém, aqueles que o fizeram afirmaram terem aprendido tais conhecimentos na escola. Para nós, isso significa que o cego, como qualquer aluno, precisa ter oportunidades de aprendizado. Dada a ausência de visão, são necessárias adaptações para que as informações visuais lhes cheguem por outras vias. Mas a capacidade de abstração do cego não é diferente da capacidade daquele que enxerga. A questão é que, independente da cegueira, para aprender, é preciso ter oportunidade de aprendizagem.

Em resumo, nos estudos apresentados sobre a educação do aluno com deficiência visual, percebemos pontos comuns: falta de recursos, falta de preparo do professor e falta de conhecimento sobre a capacidade de aprendizagem do cego. Quanto à falta de recursos, os estudos mostraram que a fala do professor constitui praticamente o único recurso para a aprendizagem do cego. Ainda que a linguagem seja fundamental no desenvolvimento, ela não consegue substituir tudo, por isso a importância de utilizar outros materiais adaptados.

Além disso, para que a linguagem seja uma fonte de informações para o aluno cego, é preciso que esteja adaptada às suas necessidades, a fim de que os conhecimentos trazidos pelo professor possam fazer sentido. Assim, notamos que a discussão sobre integração/inclusão, frequente desde a década de 1990, ainda se faz necessária. Pois não basta que os alunos cegos estejam em sala de aula. É preciso que a escola adapte-se a esse aluno. Sem a oferta de oportunidades de aprendizagem, não há garantia do direito à educação.

Ao comentar a escassez de materiais adequados para o cego, Monte Alegre (2003) desabafa: “(...) é injusto com os estudantes cegos que eles fiquem fadados a uma pedagogia espontaneísta, improvisativa e realizada por principiantes" (p.118).

Mais do que injustiça trata-se de um desrespeito às leis que asseguram os direitos dos alunos com deficiência. A emenda constitucional n. ${ }^{\circ} 12$, de 1978, afirma que "(...) é assegurado aos deficientes a melhoria de sua condição social e econômica, especialmente mediante educação especial e gratuita"; e no artigo 208, lemos no inciso III, da Constituição de 1988: “(...) atendimento educacional especializado aos portadores de deficiência, preferencialmente na rede regular de ensino".

Será que o direito do aluno com deficiência está garantido se não são dadas condições adequadas de preparação do professor e se não são feitas as adaptações necessárias para que ele seja um aluno regular realmente incluído em sala de aula comum? Para Lira e Schlindwein (2008), "a escola pode auxiliar a enfrentar as dificuldades impostas pela diferença visual em uma sociedade essencialmente visual". (p.173). É nesse sentido que acreditamos que a reflexão sobre o que é a cegueira, bem como a abertura à experiência com o aluno cego são caminhos facilitadores da aprendizagem deste aluno.

\section{IV. À guisa de conclusão}

Como destacado nas seções anteriores, a cegueira tem sido pensada unicamente pela falta e pela incapacidade. Isso é evidenciado no susto e na admiração das pessoas ao se depararem com algumas habilidades cotidianas de indivíduos cegos. O espanto e a descrença parecem ainda maiores quando se trata da formação e práticas profissionais desses últimos. São comuns comentários comparativos com cegos bem sucedidos e conclusões de que é uma vergonha que eles consigam algo grandioso enquanto nós (videntes e perfeitos...) não temos o mesmo (ou melhor) desempenho profissional. Parece existir uma expectativa de frustração para a vida do cego e o espanto está em perceber seu sucesso ou, melhor dizendo, sua capacidade de chegar ao mesmo ponto que o vidente. Essas falsas ideias evidenciam a expectativa de limitações muito maiores e mais amplas da pessoa cega do que aquelas realmente decorrentes da deficiência.

Esta concepção do cego como ser faltante dificulta muito as relações sociais da pessoa cega, principalmente pelo desconhecimento de sua real condição, o que pode causar um impacto afetivo negativo, uma vez que o imaginário social está enviesado por estereótipos de limitação e sofrimento na vida do cego.

O prognóstico desfavorável para pessoas deficientes, muitas vezes se baseia demasiadamente nas limitações da deficiência. Essa percepção organicista valoriza excessivamente o defeito orgânico. É evidente que não se trata de negar a cegueira enquanto uma limitação que exige adaptações. No entanto, há algumas décadas, pesquisadores que trabalham com cegos, tal como Amiralian (1990), questionam os resultados que mostram atrasos no desenvolvimento do deficiente visual em pesquisas comparativas com videntes. Para além da comparação, nossa proposta, de acordo com 
os autores aqui citados, é pensar em processos diferentes, com diferentes tempos de desenvolvimento, mas lembrando que o cego é capaz de aprender, simplesmente porque é um ser humano, ou seja, um ser de aprendizagem. Isso quer dizer que pais, professores e profissionais devem facilitar e possibilitar ao máximo tal aprendizagem.

\section{Referências}

Amiralian, M. L. T. M. (1990). A integração dos deficientes visuais: aspectos psicológicos e sociais. Boletim de Psicologia, 40(92/93), 61-64.

Amiralian, M. L. T. M. (1997). Compreendendo o cego: uma visão psicanalítica da cegueira por meio de desenhos-estórias. São Paulo: Casa do Psicólogo.

Amiralian, M. L. T. M. (2002). O psicólogo e as pessoas com deficiência visual. Em E. A. F. S. Masini (Org.), Do sentido, pelos sentidos, para o sentido: sentidos das pessoas com deficiência sensorial (pp. 201-208). Niterói, RJ: Intertexto.

Amiralian, M. L. T. M. (2007). A construção do eu de crianças cegas congênitas. Natureza Humana, 9(1), 129-153.

Batista, C. G. (2005). Formação de conceitos em crianças cegas: questões teóricas e implicações educacionais. Psicologia: teoria e pesquisa, 21(1), 7-15.

Batista, C. G., \& Enumo, S. R. F. (2000). Desenvolvimento humano e impedimentos de origem orgânica: o caso da deficiência visual. Em H. A. Novo \& M. C. S. Menandro (Orgs.), Olhares diversos: estudando o desenvolvimento humano (pp.157-174). Vitória: UFES, Programa de Pós-graduação em Psicologia.

Camargo, E. P., Nardi, R., \& Veraszto, E. V. (2008) A comunicação como barreira à inclusão de alunos com deficiência visual em aulas de óptica [Versão eletrônica]. Revista Brasileira de Ensino de Física, 30(3), 3401.

Caiado, K. R. M. (2003). Aluno deficiente visual na escola: lembranças e depoimentos. Campinas, SP: Autores Associados-PUC.

Constituição da República Federativa do Brasil de 1988. (1988). Brasilia. Disponível: http://www.senado.gov.br/sf/legislacao/const/

Ferrari, A. L., \& Campos, E. (2001) De que cor é o vento? Subsídios para ações educativo- culturais com deficientes visuais em museus. Belo Horizonte, MG: Prefeitura.

Kent, D. (1989). Shackled imagination: literary illusions about blindness. Journal of Visual Impairment \& Blindness,83(3), 145150.
Lei n. 5540, de 28 de novembro de 1968. (1968). Fixa normas de organização e funcionamento do ensino superior e sua articulação com a escola média, e dá outras providências. Brasília.

Lira, M. C. F., \& Schlindwein, L. M. (2008) A pessoa cega e a inclusão: um olhar a partir da psicologia histórico-cultural. Caderno Cedes, 28(75), 171-190.

Lomônaco, J. F. B., NUNES, S. S., \& SANO, W. T. (2004). Concepções de cegueira entre estudantes de Psicologia. Boletim de Psicologia, 54(120), 23-46.

Masini, E. F. S. (1994). O percebere o relacionar-se do deficiente visual: orientando professores especializados. Brasília: Coordenadoria Nacional para Integração da Pessoa Portadora de Deficiência.

Monte Alegre, P. A. C. (2003). A cegueira e a visão do pensamento. Dissertação de mestrado, Instituto de Psicologia, Universidade de São Paulo, São Paulo.

Montilha, R. C. I, Temporini, E. R., Nobre, M. I. R. S., \& Kara-José, N. (2009). Percepções de escolares com deficiência visual em relação ao seu processo de escolarização. Paidéia, 19(44), 333339.

Nunes, S. S., \& Lomônaco, J. F. B. (2008). Desenvolvimento de conceitos em cegos congênitos: caminhos de aquisição do conhecimento. Psicologia Escolar e Educacional, 12(1), 119-138.

Ochaíta, E., \& Rosa, A. (1995). Percepção, ação e conhecimento nas crianças cegas. Em C. Coll, J. Palacios \& A. Marchesi (Orgs.), Desenvolvimento Psicológico e Educação. Vol. 3-Necessidades educativas especiais e aprendizagem escolar (M.A.G. Domingues, Trad.). Porto Alegre, RS: Artes Médicas. (Trabalho original publicado em 1993).

Oliveira, J. V. G. (2002). Do essencial invisivel: arte e beleza entre os cegos. Rio de Janeiro: Revan/FAPERJ.

Rabêllo, R. S. (2003). Análise de um experimento de teatro-educação no Instituto de Cegos da Bahia: possibilidades de utilização da linguagem teatral por um grupo de adolescentes. Tese de Doutorado, Faculdade de Educação, Universidade de São Paulo, São Paulo.

Viegas, L. M., Paiva, L. H. Y., Guimarães, L. M., Leme, M. I., Morimatsu, P. M., \& Nunes, S. S. (2004). Concepções de cegueira congênita entre estudantes de pedagogia. Resumos da Jornada de Educação Especial, 7 (pp. 157-158). Marília: Fundepe.

Vygotsky, L. S. (1997). Fundamentos de Defectología. Obras Completas, tomo cinco (2a reimp.). Cuba: Editorial Pueblo y Educación. 
Recebido em: 26/02/2009

Reformulado em: 01/06/2010

Aprovado em: 08/06/2010

Sobre os autores

Sylvia Nunes (sylviasnunes@yahoo.com.br)

Universidade Federal de Itajubá, Itajubá - MG

José Fernando Bitencourt Lomônaco (jfblusp@usp.br)

Instituto de Psicologia da Universidade de São Paulo, São Paulo - SP

\section{Correspondência}

Sylvia Nunes

Rua Dr. Moacyr Vargas de Souza, 115

Jardim Filipinos Poços de Caldas- MG CEP: 37701-257. 